\title{
Interaction between root growth allocation and mycorrhizal fungi in soil with patchy $\mathrm{P}$ distribution
}

\section{Journal Article}

Author(s):

Felderer, Bernd; Jansa, Jan; Schulin, R.

Publication date:

2013-12

Permanent link:

https://doi.org/10.3929/ethz-b-000075675

Rights / license:

In Copyright - Non-Commercial Use Permitted

Originally published in:

Plant and Soil 373(1-2), https://doi.org/10.1007/s11104-013-1818-6 


\title{
Interaction between root growth allocation and mycorrhizal fungi in soil with patchy $P$ distribution
}

\author{
Bernd Felderer • Jan Jansa • Rainer Schulin
}

Received: 1 May 2013 / Accepted: 13 June 2013 /Published online: 6 July 2013

(C) Springer Science+Business Media Dordrecht 2013

\begin{abstract}
Aims and Background Many plants preferentially grow roots into P-enriched soil patches, but little is known about how the presence of arbuscular mycorrhizal fungi (AMF) affects this response.

Methods Lotus japonicus (L.) was grown in a low-P soil with (a) no additional $\mathrm{P}$, (b) homogeneous $\mathrm{P}$ (28 $\left.\mathrm{mg} \mathrm{pot}^{-1}\right)$, (c) low heterogeneous $\mathrm{P}\left(9.3 \mathrm{mg} \mathrm{pot}^{-1}\right)$, and (d) high heterogeneous $\mathrm{P}\left(28 \mathrm{mg} \operatorname{pot}^{-1}\right)$. Each $\mathrm{P}$ treatment was combined with one of three mycorrhiza treatments: no mycorrhizae, Glomus intraradices, indigenous AMF. Real-time PCR was used to assess the abundance of $G$. intraradices and the indigeneous AMF G. mosseae and $G$. claroideum.

Results Mycorrhization and $\mathrm{P}$ fertilization strongly increased plant growth. Homogeneous P supply enhanced growth in both mycorrhizal treatments, while heterogeneous $\mathrm{P}$ fertilization increased biomass production only in treatments with indigenous AMF inoculation. Preferential root allocation into P-enriched soil was significant only in absence of AMF. The abundance of AMF species was similar in P-enriched and unfertilized soil patches.
\end{abstract}

Responsible Editor: Erik J. Joner.

B. Felderer $(\bowtie) \cdot$ R. Schulin

Soil Protection Group, Institute of Terrestrial Ecosystems, ETH Zurich, Universitätstrasse 16, 8092 Zurich, Switzerland e-mail: bernd.felderer@env.ethz.ch

J. Jansa

Institute of Microbiology, Academy of Sciences of the Czech Republic, Vídeňská 1083, 14220 Praha, Czech Republic
Conclusion Mycorrhization may completely override preferential root growth responses of plants to Ppatchiness in soil. The advantage of this effect for the plants is to give roots more freedom to forage for other resources in demand for growth and to adapt to variable soil conditions.

Keywords Preferential root growth · Arbuscular mycorrhizal fungi $\cdot$ Lotus japonicus · Heterogeneous . Phosphorus $\cdot$ Root allocation

\section{Introduction}

Phosphorus $(\mathrm{P})$ is an essential macronutrient element that is limiting plant growth in many natural and cultivated soils. Many soils are deficient in plant available $\mathrm{P}$, because the availability of dissolved $\mathrm{P}$ is often limited by the low solubility of $\mathrm{Ca}, \mathrm{Fe}$ and $\mathrm{Al}$ phosphates or strong binding to specific sorption sites (Hinsinger 2001). When roots take up $\mathrm{P}$ from the rhizophere solution, re-supply from the bulk soil is limited by solubilization of $\mathrm{P}$ from the solid matrix and transport of the dissolved $\mathrm{P}$ to the roots. Diffusion is the main transport process, and diffusivity of $\mathrm{P}$ is a critical factor that often co-limits the $\mathrm{P}$ uptake rate of roots in combination with the low solubility of solid $\mathrm{P}$ phases.

The P nutrition of around $80 \%$ of all plant species benefits from a mutualistic association with arbuscular mycorrhizal fungi (Smith and Read 2008). Arbuscular mycorrhizal fungi (AMF) overcome the problem of low $\mathrm{P}$ diffusivity by growing their hyphae into soil zones not 
yet depleted in $\mathrm{P}$ and consequently exploiting a much larger soil volume than roots. While these associations are usually beneficial for both organisms, AMF can also negatively affect plant growth, depending on environmental conditions and the type of AMF-plant combination (Johnson et al. 1997; Smith et al. 2009). With increasing concentrations of soil $\mathrm{P}$ that is directly available to the roots, there is less benefit of the mycorrhizal association for the plant and thus, mycorrhizal root colonization and production of extraradical mycorrhizal hyphae generally decrease (Smith et al. 2011).

Phosphorus is usually distributed heterogeneously in soil, also at the scale of a single root system (Jackson and Caldwell 1993). This can be an important factor for plant $\mathrm{P}$ acquisition. A given amount of soluble $\mathrm{P}$ tends to be more easily available for uptake if it is locally concentrated than if it is homogeneously distributed within the volume of soil accessible to the roots (Kume et al. 2006). This beneficial effect of heterogeneous $\mathrm{P}$ distribution is attributed to the following reasons: (a) Sorption strength generally decreases with increasing concentration, and higher $\mathrm{P}$ concentration gradients result in locally larger diffusive fluxes of $\mathrm{P}$ in the soil solution (Kovar and Barber 1989). (b) Local enrichment allows to reduce the average length of diffusive pathways for soil-root transfer of $\mathrm{P}$ by preferential root allocation (morphological plasticity) in P-enriched soil patches (Robinson 1994). (c) It also allows for increased $P$ uptake efficiency by concentrating $\mathrm{P}$ membrane transporter activity in zones of high soil $\mathrm{P}$ availability (physiological plasticity) within less root mass than in case of homogeneous soil P distribution (Jackson et al. 1990). (d) Similarly, the efficiency of $\mathrm{P}$ acquisition by plants can be increased by preferential growth of extraradical mycorrhizal hyphae (Hodge 2005). Preferential allocation of roots into nutrient-enriched patches is the phenomenon that is best investigated among the strategies of plants to adapt to heterogeneous distribution of resources in soil. The degree to which the spatial distribution of roots responds to the uneven distribution of a nutrient in soil can be quantified by the so-called 'precision of root allocation', defined as the difference in root mass density between a $\mathrm{P}$ enriched patch of soil and an unfertilized control patch in relation to the overall root mass density (Einsmann et al. 1999). It depends on plant species and plant nutrient status (Robinson 1994; Ma and Rengel 2008), as well as on nutrient type, degree of heterogeneity and patch sizes (Robinson 1994; Farley and Fitter 1999; Wijesinghe and Hutchings 1999).
Preferential allocation of mycorrhizal hyphae and effects of AMF on plant growth in soil with heterogeneous $\mathrm{P}$ distribution has been investigated much less than preferential root growth. Several AMF species were found to grow extraradical hyphae preferentially into Penriched soil compartments (Cavagnaro et al. 2005; Shi et al. 2011). However, roots were excluded from the Penriched soil by screens, as the objective was to study the potential contribution of AMF to plant $\mathrm{P}$ acquisition under conditions of exclusive $\mathrm{P}$ availability to AMF and not hyphal allocation in unrestrained competition with plants roots, which may have led to a different outcome of the experiment (Smith et al. 2009). Hodge (2005) hypothesized that AMF may be more flexible in responding to temporary patches of increased nutrient availability than roots, as the metabolic cost of hyphal length growth is much less because of their smaller diameter. Providing assimilates for preferential allocation of AMF hyphae could therefore be more economical for plants associated with AMF than investing into own root growth to explore and exploit P-enriched patches, assuming that plant growth is simultaneously limited by soil resources and assimilates as predicted by the multiple limitation hypothesis (Gleeson and Tilman 1992; Tibett, 2000). 'Delegating' soil P mining to AMF would have the advantage that the roots would have more freedom to forage for other nutrients and water in soil zones with low $\mathrm{P}$ availability. Investigating effects of AMF on preferential root growth in P-enriched patches accessible to roots and mycorrhizal hyphae, Cui and Caldwell (1996) in fact found that preferential allocation of Agropyron desertorum roots into N and P-enriched patches was decreased in mycorrhizal compared to nonmycorrhizal plants and that mycorrhization increased $\mathrm{P}$ uptake from soil with heterogeneous, but not with homogeneous $\mathrm{P}$ distribution. The authors suggested that extraradical mycorrhizal hyphae pre-empted the Penriched soil and eventually improved plant P uptake, but did not investigate the abundance of extraradical or intraradical hyphae. On the other hand, there may also be conditions in which locally increased P supply makes direct $\mathrm{P}$ uptake by the roots more efficient for a plant than $P$ acquisition through AMF hyphae, as the strength of $\mathrm{P}$ adsorption to mineral or organic soil phases decreases with concentration.

Using Lotus japonicus (L.) as a model plant, the aim of this study was to investigate interactions between plant growth, spatial allocation of roots, root colonization by AMF and development of extraradical 
hyphae in soil with heterogeneous $\mathrm{P}$ distribution. The research questions were: (a) Does plant growth enhancement by AMF depend on the spatial distribution of soil P? (b) In case of preferential root allocation into P-enriched soil, how is it influenced by AMF? We addressed these questions by performing a factorial container experiment with constructed soil $\mathrm{P}$ distributions, comparing treatment combinations with heterogeneous and homogeneous $\mathrm{P}$ distribution at different levels of total P application and three mycorrhizal treatments of the sterilized test soil: no AMF inoculation, inoculation with Glomus intraradices, and reinoculation with indigenous mycorrhizal fungi. No screens were used to separate P-enriched from untreated P-poor soil, so all soil was accessible for both the roots and AMF hyphae.

\section{Materials and methods}

\section{Soil preparation and AMF treatments}

The experimental soil was collected from an experimental site of a collaborative multidisciplinary research project investigating structures and processes of initial ecosystem development (Gerwin et al. 2009). This soil had developed from a Pleistocene sediment extracted from the forefield of an open cast mine near Cottbus (Welzow Süd, Germany) and consisted of $88.9 \%$ sand, $8.8 \%$ silt and $2.3 \%$ clay. The sand consisted of $88.9 \%$ sand, $8.8 \%$ silt and $2.3 \%$ clay. The organic carbon content was $0.17 \%$, the calcium carbonate content was $1.34 \%$, and the $\mathrm{pH}$ was 8.8 . Bicarbonate-extractable (Olsen et al. 1954) P was low with $1.9 \mathrm{mg} \mathrm{kg}^{-1}$ soil and total soil $\mathrm{N}$ content $(\mathrm{CN}-$ Analyzer) was even below the detection limit. The soil was sterilized by gamma-irradiation $(25-75 \mathrm{kGy})$ and inoculated with AMF-free solution extracted from non-sterilized soil by filtering a soil-water suspension with a $45 \mu \mathrm{m}$ mesh. The aim of this inoculation was to re-introduce the non-fungal indigenous microbial soil flora. After this inoculation, the soil was partitioned into three batches, one each for the following three rates of $\mathrm{P}$ application in form of $\mathrm{Ca}$ monophosphate $\left(\mathrm{Ca}\left(\mathrm{H}_{2} \mathrm{PO}_{4}\right)_{2} \cdot \mathrm{H}_{2} 0\right)$ solution: 0,20 or $60 \mathrm{mg} \mathrm{P}$ per $\mathrm{kg}$ soil. Each soil batch was further partitioned into three sub-batches for inoculation with indigenous AMF ('ind. AMF' treatment), G. intraradices ('G. intra' treatment) and non-viable AMF ('no AMF' treatment). In all three AMF treatments, inoculum consisting of spores, colonized root fragments (chopped to less than $2 \mathrm{~cm}$ in length) and soil attached to the roots as well as extraradical mycelium fragments was thoroughly mixed into the sterilized soil $(\mathrm{w} / \mathrm{w})$ at a ratio of $5 \mathrm{~g}$ inoculum per $100 \mathrm{~g}$ mixture. The inoculum of $G$. intraradices had been produced under glasshouse conditions in open-pot cultures of $G$. intraradices Schenck \& Smith isolate BEG 158 using potting mix planted with leek (Allium porrum L.). The inoculum of indigenous AMF was obtained from a previous pot culture of $L$. corniculatus using the experimental soil. For the no AMF treatment, indigenous AMF inoculum obtained from this culture was applied after gamma sterilization.

\section{Filling of containers}

Teflon-coated aluminium containers of $27 \times 27 \times 1.4 \mathrm{~cm}$ size $(\mathrm{L} \times \mathrm{H} \times \mathrm{B})$ were used for the experiments. To fill them with the experimental soils, the containers were laid down on one side and removed the upward looking lateral wall of the other side. Then, P- and AMF-treated soil (see above) was taken from the respective (sub)batches and filled into the containers in three vertical bands or sections of equal width $(9 \times 27 \mathrm{~cm})$, according to the scheme of the selected treatment (see below). Corresponding to the position of the sections, when looking from above at the open container, they will be referred to as 'left' (LS), 'middle' (MS) and 'right' (RS) sections. The mycorrhizal inoculant was always the same in the three sections of a given container and differed only between treatments. Heterogeneous conditions were established only with regard to $\mathrm{P}$ distribution in the respective treatments. In the 2 homogeneous $\mathrm{P}$ treatments (see next section) all soil filled into the three sections of a container had the same $\mathrm{P}$ concentration. In the 2 heterogeneous $P$ treatments (see next section) soil fertilized with either 20 or $60 \mathrm{mg} \mathrm{P} \mathrm{kg}^{-1}$ was filled into the right container sections and soil with no added $\mathrm{P}$ into the left and middle sections. No barriers or screens were installed to separate the three soil sections physically. After filling, the lateral wall was mounted and the container put into upright position again. The total mass of soil filled into each container was determined by weighing. It varied between 1.33 and $1.45 \mathrm{~kg}$.

\section{Experimental design}

Three AMF treatments were applied in combination with $4 \mathrm{P}$ treatments in a fully randomized factorial 
design. For each of the mycorrhizal treatments (no AMF, G. intra, ind. AMF), $4 \mathrm{P}$ treatments were established: 0 P HOM (homogeneous soil with no P addition); $28 \mathrm{P}$ HOM (homogeneous soil with addition of $20 \mathrm{mg} \mathrm{P} \mathrm{kg}^{-1}$, equivalent to $28 \mathrm{mg} \mathrm{P}$ per container); 9.3 P HET (heterogeneous filling using soil with $20 \mathrm{mg} \mathrm{P} \mathrm{kg}^{-1}$ for the right container section, equivalent to $9.3 \mathrm{mg} \mathrm{P}$ per container); and $28 \mathrm{P}$ HET (heterogeneous filling using soil with $60 \mathrm{mg} \mathrm{P} \mathrm{kg}^{-1}$ for the right container section, equivalent to $28 \mathrm{mg} \mathrm{P}$ per container ). Thus, one ot the heterogeneous treatments (9.3 P HET) had the same soil $\mathrm{P}$ concentration in the fertilized soil section as in the homogeneous fertilization treatment (28 P HOM), while in the other (28 P HET) the same amount of $\mathrm{P}$ was applied per container, but concentrated in one third of the soil packing. Each of the 12 treatment combinations was replicated 4 times.

Plant establishment and growth conditions

Seeds of L. japonicus ecotype GIFU (Department of Molecular Biology, University of Aarhus, Denmark) were sterilized with $1 \%$ of hypochlorite solution (diluted commercial bleach) and germinated on filter paper. A single seedling was planted in the middle of each aluminium container, equidistant to the two lateral sections LS and RS. Plants were grown in a climate chamber with relative aerial humidity of $60 \%$ with a $16 \mathrm{~h}: 8 \mathrm{~h}$ day/night cycle with $21 / 16^{\circ} \mathrm{C}$ temperature, respectively. During the day the photon flux was $250 \mu \mathrm{mol} \mathrm{m} \mathrm{m}^{-2} \mathrm{~s}^{-1}$. Plants were watered to $50 \%$ waterholding capacity (approx. $100 \mathrm{hPa}$ water suction). All plants in the experiment developed functioning nodules for $\mathrm{N}$-fixation. We did not to supply other nutrients than P to keep nutrient conditions as closely as possible to the conditions of the soil in the field in the interest of the before-mentioned joint project. The concentrations of $\mathrm{N}, \mathrm{Ca}, \mathrm{Mg}, \mathrm{K}, \mathrm{Fe}, \mathrm{Mn}$, and $\mathrm{Zn}$ measured in the harvested plant shoots at the end of the experiment did not indicate that one of these elements was limiting plant growth (data not shown).

Sampling and chemical soil analysis

For initial characterization of the experimental soil, soil texture was determined using the hydrometer method after wet oxidation of the organic matter using hydrogen peroxide (FAL 1996b). Organic matter content was determined using the dichromate method (FAL 1996c) and carbonate content was measured by volumetric analysis of the $\mathrm{CO}_{2}$ that evolved after addition of $4 \mathrm{M}$ $\mathrm{HCl}$ to the soil (FAL 1996a). Soil $\mathrm{pH}$ was measured in a 1:2.5 soil water suspension (FAL 1996d). At the end of the experiment after 104 days of growth, shoots were harvested by clipping them at the soil surface, dried to constant weight at $60{ }^{\circ} \mathrm{C}$, weighed and stored in an exsiccator until they were analyzed for $\mathrm{P}, \mathrm{N}, \mathrm{Ca}, \mathrm{Mg}$, $\mathrm{K}, \mathrm{Cu}, \mathrm{Fe}, \mathrm{Mn}$ and $\mathrm{Zn}$ concentrations. After removal of the shoots, subsamples were collectedfrom each sectionat 4, 8, 12 and $16 \mathrm{~cm}$ depth using a thin-walled metal tube. These subsamples were pooled to one composite sample per section and frozen at $-23{ }^{\circ} \mathrm{C}$. The soil packings were then divided with a knife into right, middle and left sections according to the original filling design, and the roots were sampled by thoroughly washing the soil from the roots. The roots were imaged using a scanner (EPSON, Expression 10000XL) and frozen at $-23{ }^{\circ} \mathrm{C}$. Three days later, the root samples were lyophilized to constant weighed, cut into small pieces and stored in an exsiccator until they were analyzed for AMF, dry weight, root length, and nutrient concentrations. Root samples were digested in $15 \mathrm{ml}$ $69 \% \mathrm{HNO}_{3}$ in a heating block at $120{ }^{\circ} \mathrm{C}$ for 2 hours. Phosphorus was analyzed in the experimental solutions by means of ICP-OES (Vista-MPX, Varian). Nitrogen was analyzed using a $\mathrm{CN}$ analyzer (Flash EA, Thermo Electron Corporation). In the "0 P HOM non-myc" treatment no $\mathrm{N}$ analysis was possible because all root material was consumed by the other analyses. Root length was determined in the scanned root images using Win-Rhizo software (Regent Instruments Canada Inc., Ottawa, Canada). Except for imaging and AMF analysis, shoot samples were analyzed in the same way as root samples. Like the plant samples, the soil samples were lyophilized and stored in an exsiccator until analysis for dry weight as well as $\mathrm{P}$ and $\mathrm{N}$ concentrations.

AMF analysis of root and soil samples

The abundance of individual AMF taxa in root and soil samples was assessed by means of quantitative real-time PCR (qPCR). Molecular quantification is now firmly established in microbial ecology and also frequently applied to quantify AMF (Jansa et al. 2008; Kiers et al. 2011; Gryndler et al. 2012; Thonar et al. 2012). Briefly, subsamples of the lyophilized soil and root samples were milled in a ball mill MM 200 (Retsch). Then, DNA was extracted from aliquots of 15-20 mg 
milled root sample and $500 \mathrm{mg}$ milled soil sample using the DNeasy Plant Mini Kit (Qiagen) and the PowerSoil DNA Isolation Kit (MoBio), respectively. All samples were spiked with $2 \times 10^{10}$ copies of internal DNA standard (linearized plasmid carrying a fragment of the Cassava Mosaic Virus, GenBank accession AJ427910) before DNA extraction. The analyses were carried out using Roche chemistry (Lightcycler TaqMan Master) and Lightcycler 2.0 (Roche). Preliminary analyses showed that Glomus mosseae and G. claroideum were detectable using the existing qPCR markers in root samples from the soil re-inoculated with indigenous AMF. The markers used were targeting the nuclear large ribosomal subunit (LSU) of Glomus intraradices, G. claroideum, and G. mosseae. The marker system for quantification of internal standard recovery was described by Thonar et al. (2012), and the mitochondrial LSU marker for $G$. intraradices (mt5) was described by Couillerot et al. (2012). The results of the qPCR (Cq values) were converted to copy numbers of individual AMF taxa per unit weight of roots and corrected for extraction efficiency using the internal standard recovery as described in Thonar et al. (2012).

Data analysis and statistics

The precision (Pr) of root and AMF allocation was determined by calculating the differences in root dry weight, root length, extraradical and intraradical LSU copy numbers between RS and LS and dividing them by the total of the respective root or AMF parameter for the entire container. In addition, we estimated the precision of extraradical and intraradical hyphae allocation relative to root mass by taking the respective differences in LSU copy numbers per unit root mass between the two lateral sections RS and LS and dividing them by the average density of the respective LSU copies in the entire container (i.e. total numbers of LSU copies in the container divided by total root mass). Using regression analysis, $\mathrm{p}$-values were calculated to assess whether the precision of root and AMF allocation calculated in terms of these parameters was significantly different from 0 or not, taking $p<0.05$ as criterion for non-random, i.e. preferential allocation.

Differences between treatments were assessed by Analysis of Variance (ANOVA) using the statistical software package $\mathrm{R}$ ( $\mathrm{R}$ developmental Core Team, 2008). For shoot and root dry weights the analysis was performed on square root transformed data in order to fulfill the normal distribution assumption of the test. For the same reason, the analysis of LSU copy numbers was performed on log-transformed data. Pairwise comparison of differences between treatment means were determined by means of the Least Significant Differences (LSD) method, if main effects and interactions between the main effects were significant (ANOVA); otherwise a Bonferroni correction was applied.

\section{Results}

Biomass production

Treatment effects on shoot and root biomass were similar (Fig. 1). Mycorrhization led to a strong increase in biomass production (Fig. 1), except for the treatment with $G$ intraradices in combination with heterogeneous $\mathrm{P}$ application, where biomass did not differ from the same P treatment without AMF inoculation. Compared to the respective treatments without $\mathrm{P}$ fertilization, $\mathrm{P}$ application always increased biomass, except for the heterogeneous $\mathrm{P}$ applications to soil inoculated with $G$.

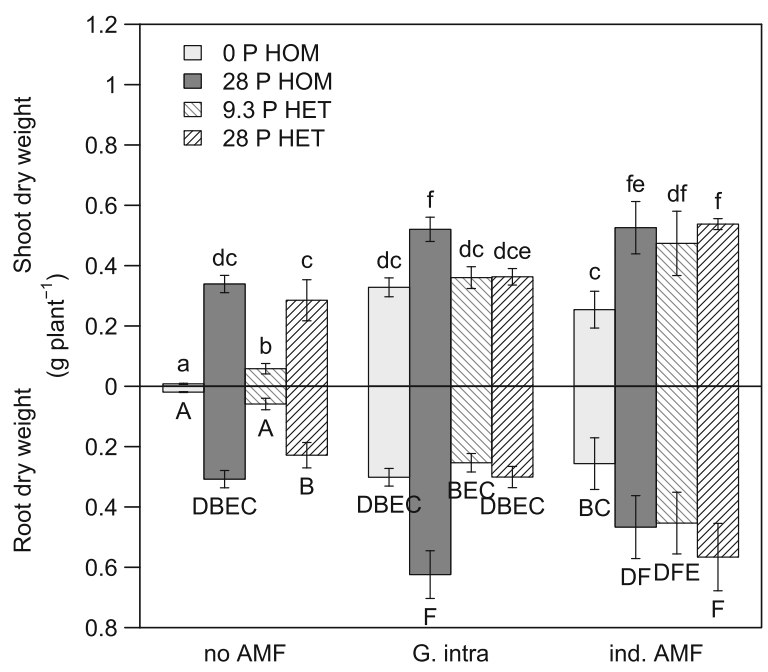

Fig. 1 Shoot and root dry weights (g plant $\left.{ }^{-1}\right)$ of L. japonicus grown in soil without AMF (no AMF), soil inoculated with $G$. intraradices (G. intra) and soil re-inoculated with indigenous AMF (ind. AMF) after sterilization for the four P treatments: no fertilization (0 P HOM), homogeneous P supply (28 P HOM), low heterogeneous P supply (9.3 P HET), high heterogeneous $\mathrm{P}$ supply (28 P HET). Error bars give the standard error of the means. Different letters indicate significantly different means according to least significant difference (LSD) multiple range test following significant ANOVA $(p<0.05)$ 
intraradices. There was no significant difference in biomass production between the treatments with high heterogeneous and homogeneous P supply (i.e. when the same total amount of $\mathrm{P}$ was applied) in combination with indigenous or no AMF, while biomass production was lower in the heterogeneous than in the homogeneously fertilized treatments with $G$. intraradices.

\section{$\mathrm{P}$ concentration}

Treatment effects on root and shoot $\mathrm{P}$ concentrations were in many respects similar to the described pattern of biomass responses, although the effects on $\mathrm{P}$ concentrations were generally less distinct than those on biomass. Overall, mycorrhization and $\mathrm{P}$ application increased plant $\mathrm{P}$ concentrations. For the root $\mathrm{P}$ concentrations also the interaction of AMF and $\mathrm{P}$ treatment had a significant effect ( $p<0.05$, ANOVA, Fig. 2). Pairwise comparison (Bonferroni corrected for the shoots and LSD corrected for the roots, $p<0.05$ ) revealed a significant effect of mycorrhization only in the case of the unfertilized control,

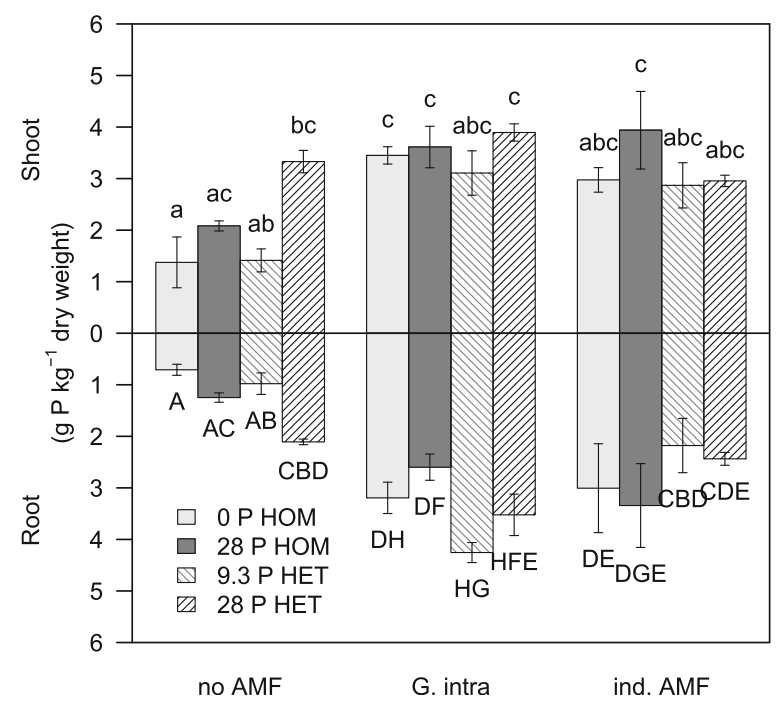

Fig. 2 Phosphorus concentrations of shoots and roots $\left(\mathrm{g} \mathrm{P} \mathrm{kg}^{-1}\right.$ dry weight) of L. japonicus grown in soil without AMF (no AMF), soil inoculated with G. intraradices (G. intra) and soil reinoculated with indigenous AMF (ind. AMF) after sterilization for the four P treatments: no fertilization (0 P HOM), homogeneous P supply (28 P HOM), low heterogeneous P supply (9.3 P HET), high heterogeneous P supply (28 P HET). Error bars give the standard error of the means. Different letters indicate significantly different means as determined by Bonferroni corrected multiple comparison $(p<0.05)$ for shoot $\mathrm{P}$ concentrations by least significant difference (LSD) multiple range tests following ANOVA $(p<0.05)$ for root $\mathrm{P}$ concentrations where inoculation with $G$. intraradices increased shoot and root $\mathrm{P}$ concentration compared to the nonmycorrhizal plants. Application of $\mathrm{P}$ had a significant effect on shoot and root $\mathrm{P}$ concentration only in the nonmycorrhizal plants when P was applied heterogeneously at the higher of the two experimental levels. No P treatment effect on shoot or root $\mathrm{P}$ concentrations was found in the mycorrhizal plants.

\section{Precision of root allocation}

Treatment effects on the precision of root allocation were similar for root length and root dry weight (Fig. 3, Table 1). Both, root biomass and root length were significantly increased in the P-enriched soil sections in the heterogeneous $\mathrm{P}$ treatments when no viable AMF had been added to the soil. The precision of root biomass allocation was also increased in the treatments with lowlevel heterogeneous $\mathrm{P}$ application, when the soil was inoculated with indigenous AMF. This effect was only rather weak, however, and similar in magnitude as the slightly negative precision of root length allocation in the homogeneously fertilized treatment in the absence of mycorrhizae. As soil conditions were homogeneous in the latter case, we consider these effects as false positives.

\section{Abundance of mycorrhizal gene copies}

In the treatments inoculated with $G$. intraradices alone, $\mathrm{P}$ fertilization level and distribution did neither affect the average densities of mitochondrial or nuclear intrararadical LSU copies per unit root mass, nor the total numbers of mitochondrial or nuclear extraradical LSU copies per container (Table 2). The only significant P treatment effect on LSU copy numbers of $G$. intraradices was that the density of extraradical mitochondrial LSU copies per unit root mass was lower in the treatment with homogeneous $\mathrm{P}$ fertilization than in the treatments with heterogeneous or no $\mathrm{P}$ application. The densities of intraradical LSU copies and of extraradical nuclear LSU copies per unit root mass showed a similar, though at $p=0.05$ statistically not significant effect (Table 2). In the treatments with indigenous AMF, P fertilization had some effect on the density of intraradical LSU copies per unit root mass and on the total number of extraradical LSU copies produced by $G$. mosseae, but not on the LSU of $G$. claroideum (Table 2). The densities of intraradical and extraradical G. mosseae LSU copies per unit root mass 
a

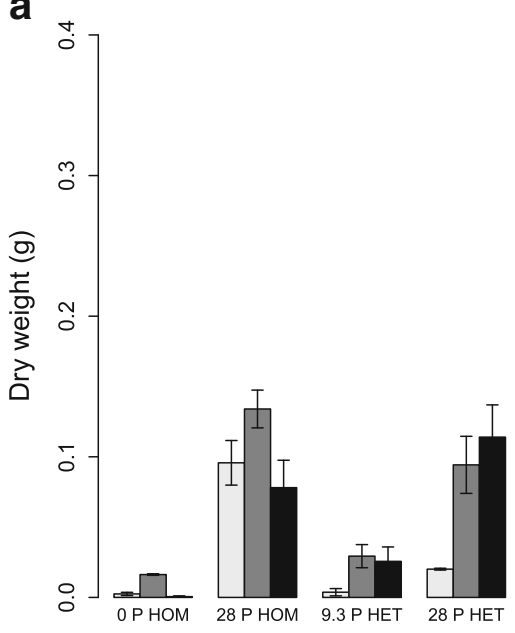

No AMF

b

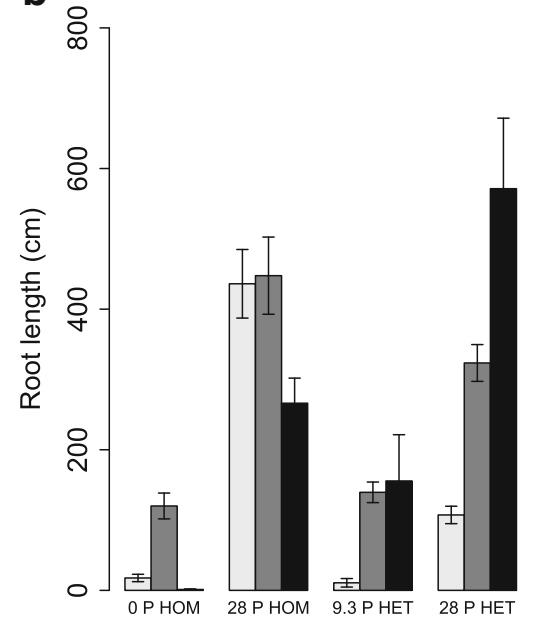

No AMF
Root dry weight

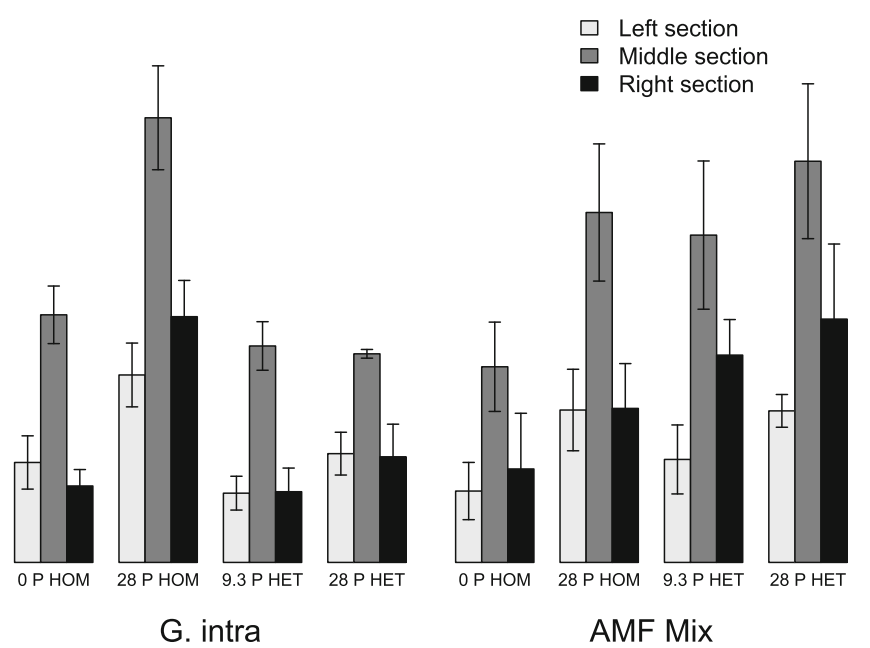

Root length

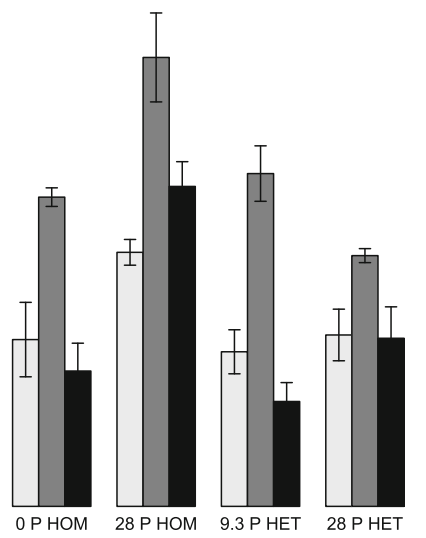

G. intra

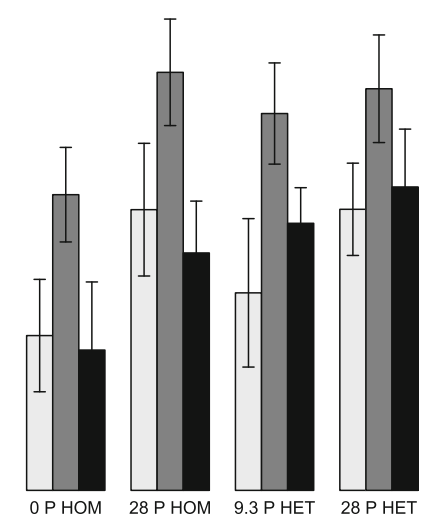

AMF Mix
Fig. 3 (a) Root biomass $\left(\mathrm{g} \mathrm{plant}^{-1}\right.$ ) and (b) root length $(\mathrm{cm}$ plant $^{-1}$ ) in the three sections of the containers (LS left, MS middle, RS right) for L. japonicus grown in soil without AMF (no AMF), soil inoculated with $G$. intraradices (G. intra) and soil reinoculated with indigenous AMF (ind. AMF) after

as well as the density of extraradical G. mosseae LSU copies per unit soil mass were lower in the unfertilized treatment than in the fertilized treatments.

Precision of mycorrhizal gene copy numbers and root-related densities

The P treatments had generally no influence on the precision of LSU copy allocation, neither for the nuclear nor the mitochondrial genes, (Table 3, Figs. 4 and 5). sterilization for the four $\mathrm{P}$ treatments: no fertilization (0 P HOM), homogeneous P supply (28 P HOM), low heterogeneous P supply (9.3 P HET), high heterogeneous P supply (28 P HET). In the heterogeneous $\mathrm{P}$ treatments $\mathrm{P}$ was added only to the right sections (RS)

Only the precision of extraradical LSU copies produced by $G$. claroideum per unit root mass showed a significant $\mathrm{P}$ fertilization effect, as relatively more copies were allocated in the lateral soil section without than in the section with P application in the heterogeneous treatments. This effect was not strong, however, and of similar magnitude as also observed in the homogeneous $\mathrm{P}$ treatments with $G$. intraradices, where extraradical nuclear LSU copies were more abundant without detectable reason in the left than in the right section. 
Table 1 Precision of root dry weigth and root length allocation in L. japonicus grown in soil without AMF (no AMF), soil inoculated with $G$. intraradices (G. intra) and soil reinoculated with indigenous AMF (ind. AMF) for the four P treatments: no fertilization (0 P HOM), homogeneous P supply (28 P HOM), low heterogeneous $\mathrm{P}$ supply (9.3 P HET), high heterogeneous $\mathrm{P}$ supply (28 P HET). The precision values gives the differences in root length or root dry weight between the right and the left section of a container divided by the total root length or dry weight in all three sections (.i.e. including middle section) of the container

\begin{tabular}{|c|c|c|c|c|c|c|c|c|c|}
\hline & & \multicolumn{4}{|c|}{ Root dry weight } & \multicolumn{3}{|c|}{ Root length } & \\
\hline & & Precision & Std.e & $P$-value & & Precision & Std.e. & $P$-value & \\
\hline \multirow[t]{4}{*}{ no $\mathrm{AMF}$} & 0 P HOM & -0.10 & 0.07 & 0.183 & $\mathrm{a}$ & -0.11 & 0.06 & 0.088 & $a b$ \\
\hline & $28 \mathrm{P} \mathrm{HOM}$ & -0.06 & 0.07 & 0.406 & $\mathrm{a}$ & -0.15 & 0.06 & $0.026^{*}$ & $\mathrm{~b}$ \\
\hline & 9.3 P HET & 0.31 & 0.07 & $0.000 * * *$ & $\mathrm{~b}$ & 0.39 & 0.06 & $0.000 * * *$ & $\mathrm{c}$ \\
\hline & 28 P HET & 0.40 & 0.08 & $0.000 * * *$ & $\mathrm{~b}$ & 0.45 & 0.07 & $0.000 * * *$ & $\mathrm{c}$ \\
\hline \multirow[t]{4}{*}{ G. intra } & 0 P HOM & -0.05 & 0.07 & 0.486 & $\mathrm{a}$ & -0.05 & 0.06 & 0.448 & abd \\
\hline & $28 \mathrm{P} \mathrm{HOM}$ & 0.07 & 0.02 & 0.350 & ac & 0.06 & 0.06 & 0.337 & $\mathrm{ad}$ \\
\hline & 9.3 P HET & -0.00 & 0.07 & 0.977 & $\mathrm{ac}$ & -0.09 & 0.06 & 0.181 & $a b$ \\
\hline & 28 P HET & -0.02 & 0.07 & 0.813 & $\mathrm{ac}$ & -0.01 & 0.06 & 0.878 & abd \\
\hline \multirow[t]{4}{*}{ ind. AMF } & 0 P HOM & 0.00 & 0.07 & 0.973 & $\mathrm{ac}$ & -0.05 & 0.06 & 0.472 & abd \\
\hline & $28 \mathrm{P} \mathrm{HOM}$ & -0.01 & 0.07 & 0.866 & ac & -0.04 & 0.06 & 0.515 & $a b d$ \\
\hline & 9.3 P HET & 0.18 & 0.08 & $0.033^{*}$ & $\mathrm{bc}$ & 0.11 & 0.07 & 0.138 & $\mathrm{~d}$ \\
\hline & 28 P HET & 0.08 & 0.07 & 0.274 & $\mathrm{ac}$ & 0.01 & 0.06 & 0.839 & abd \\
\hline
\end{tabular}

Positive values indicate preferential root allocation to the P-enriched soil sections in the heterogeneous $\mathrm{P}$ treatments. Regression analysis was used to determine if precision was significantly different from zero. ${ }^{*} p<0.05, * * p<0.01$. Different letters indicate significant differences between means according to least significant difference (LSD) multiple range post-hoc test following ANOVA $(p<0.05)$.

\section{Discussion}

AMF and P fertilization enhanced growth of L. japonicus

The results show that the growth of Lotus japonicus was severely inhibited by lack of P in the unfertilized soil and in absence of viable AMF. Given the low level of available $\mathrm{P}$ in the experimental soil, this was in agreement with expectation. Inoculation with AMF without additional $\mathrm{P}$ supply reduced this limitation to a similar extent as the high rate of total $\mathrm{P}$ application in our experiment. The fact that $\mathrm{P}$ fertilization in combination with the indigenous AMF treatment resulted in still larger biomass than without AMF treatment suggests that none of the experimental treatments with $\mathrm{P}$ applications alone was sufficient to fully alleviate the $\mathrm{P}$ limitation of plant growth. In fact, an average soil $\mathrm{P}$ fertilization rate of $20 \mathrm{mg} \mathrm{kg}^{-1}$ is still rather low compared to rates required for maximum growth that have been reported for other legumes (Demiranda et al. 1989; Abbott et al. 1984; Schweiger et al. 1995).
While P was clearly limiting the growth of mycorrhizal plants grown in unfertilized soil, it cannot be deduced from our results whether P was still growthlimiting in the heterogeneous $\mathrm{P}$ treatments when AMF were present. Root $\mathrm{P}$ concentrations were higher and shoot $\mathrm{P}$ concentrations not lower in the heterogeneous $\mathrm{P}$ treatments with $G$. intraradices than with indigenous AMF, while more biomass was produced in the latter. This could mean that a factor other than $\mathrm{P}$ became limiting with increasing $\mathrm{P}$ supply in the heterogeneous treatments and that the indigenous AMF was more efficient to remove this limitation than $G$. intraradices. Another possible explanation, further discussed below, is that $G$. intraradices itself limited $\mathrm{P}$ acquisition by the plants and that the high $\mathrm{P}$ concentrations in the root samples were due to $\mathrm{P}$ stored in intraradical fungal tissue not available to the plants (Kiers et al. 2011). The partitioning of $\mathrm{P}$ between fungus and root cells depends on $\mathrm{P}$ supply and differs widely among AMF species and could explain differences in total root $\mathrm{P}$ concentrations between the mycorrhizal treatments in our experiment. 
Table 2 Natural logarithms of the numbers of ribosomal subunit (LSU) copies of AMF hyphae in roots (intraradical) and soil (extraradical) in the $4 \mathrm{P}$ treatments: no fertilization (0 P HOM), homogeneous P supply (28 P HOM), low heterogeneous P supply (9.3 P HET), high heterogeneous P supply (28 P HET)

\begin{tabular}{|c|c|c|c|c|}
\hline & & \multirow{2}{*}{$\begin{array}{l}\text { Intraradical Hyphae } \\
\mathrm{LSU}^{-1} \text { copy number } \\
\mathrm{mg}^{-1} \text { root dry weight }\end{array}$} & \multicolumn{2}{|l|}{ Extraradical Hyphae } \\
\hline & & & $\begin{array}{l}\text { LSU copy number } \\
\mathrm{mg}^{-1} \text { soil }\end{array}$ & $\begin{array}{l}\text { LSU copy number } \mathrm{mg}^{-1} \\
\text { root dry weight }\end{array}$ \\
\hline \multirow[t]{4}{*}{ G. claroideum } & 0 P HOM & $11.02( \pm 0.27)$ & $6.46( \pm 0.44)$ & $8.37( \pm 0.40)$ \\
\hline & 28 P HOM & $10.29( \pm 0.27)$ & $6.59( \pm 0.44)$ & $7.81( \pm 0.40)$ \\
\hline & 9.3 P HET & $10.67( \pm 0.31)$ & $6.94( \pm 0.51)$ & $8.13( \pm 0.47)$ \\
\hline & 28 P HET & $10.13( \pm 0.31)$ & $7.20( \pm 0.44)$ & $8.17( \pm 0.40)$ \\
\hline \multirow[t]{4}{*}{ G. mosseae } & 0 P HOM & $8.56( \pm 0.60) \mathrm{a}$ & $3.56( \pm 0.48) \mathrm{a}$ & $5.45( \pm 0.45) \mathrm{a}$ \\
\hline & $28 \mathrm{P} \mathrm{HOM}$ & $11.34( \pm 0.60)$ & $7.32( \pm 0.48)$ & $8.54( \pm 0.45)$ \\
\hline & 9.3 P HET & $11.71( \pm 0.70)$ & $6.60( \pm 0.56)$ & $7.78( \pm 0.52)$ \\
\hline & 28 P HET & $11.21( \pm 0.70)$ & $6.36( \pm 0.48)$ & $7.32( \pm 0.45)$ \\
\hline \multirow[t]{4}{*}{ G. intraradices (nuclear DNA) } & 0 P HOM & $13.42( \pm 0.36)$ & $7.46( \pm 0.31)$ & $9.01( \pm 0.31)$ \\
\hline & $28 \mathrm{P} \mathrm{HOM}$ & $13.50( \pm 0.36)$ & $7.73( \pm 0.31)$ & $8.57( \pm 0.31)$ \\
\hline & 9.3 P HET & $14.50( \pm 0.45)$ & $7.48( \pm 0.31)$ & $9.22( \pm 0.31)$ \\
\hline & 28 P HET & $14.00( \pm 0.36)$ & $7.83( \pm 0.31)$ & $9.40( \pm 0.31)$ \\
\hline \multirow[t]{4}{*}{ (mitochondrial DNA) } & 0 P HOM & $12.88( \pm 0.38)$ & $6.60( \pm 0.31)$ & $8.15( \pm 0.32)$ \\
\hline & 28 P HOM & $12.50( \pm 0.38)$ & $6.06( \pm 0.31)$ & $6.89( \pm 0.32) \mathrm{a}$ \\
\hline & 9.3 P HET & $13.32( \pm 0.44)$ & $6.29( \pm 0.31)$ & $8.03( \pm 0.32)$ \\
\hline & 28 P HET & $13.15( \pm 0.38)$ & $6.67( \pm 0.31)$ & $8.22( \pm 0.32)$ \\
\hline
\end{tabular}

LSU copy numbers for G. claroideum and G. mossea were determined in the treatments inoculated with the indigenous AMF mixture. Mitochondrial and nuclear LSU copy numbers of $G$. intraradices were determined only for the treatments in which the soil was inoculated with $G$. intraradices alone. Different letters indicate significantly different means according to least significant difference (LSD) multiple range post-hoc test following significant ANOVA $(p<0.05)$. Both root and soil samples from nonmycorrhizal treatments yielded undetectable LSU copy numbers for all tested AMF taxa and thus not shown here.

Preferential allocation of roots into P-enriched patches was inhibited by mycorrhizal fungi

In the absence of AMF, root growth was preferentially allocated to P-enriched soil sections in the heterogeneous $\mathrm{P}$ treatments. With AMF inoculation this response disappeared. This effect may be attributed to the enhanced availability of soil $\mathrm{P}$ also in the unfertilized sections of the containers for roots associated with AMF. In mycorrhizal roots the contrast in $\mathrm{P}$ availability between $\mathrm{P}$ fertilized and unfertilized soil would have been considerably reduced in comparison to the treatments without AMF, as judged from the magnitude of the AMF effects on plant growth and $\mathrm{P}$ uptake in the treatments without fertilization. Ma and Rengel (2008) found in Triticum aestivum L. that the precision of root allocation decreased with enhanced P status. Also Cui and Caldwell (1996) who studied root length growth in Agropyron desertorum found that preferential root allocation into P-enriched soil patches decreased in the presence of AMF. But in the study of Cui and Caldwell (1996) this AMF effect was rather moderate in comparison to our experiment, where preferential root allocation nearly or even completely disappeared in presence of AMF. This strong AMF effect on preferential root allocation is particularly remarkable in the case of the $G$. intraradices treatments. As the $\mathrm{P}$ fertilization effects show, $\mathrm{P}$ was still limiting plant growth even in the presence of AMF when no P fertilizer was supplied, and thus some preferential root allocation, as observed in the heterogeneous low $\mathrm{P}$ treatment with indigenous AMF, could still have been beneficial for the plants by enhancing $\mathrm{P}$ acquisition.

An explanation for the particularly strong inhibition effect of $G$. intraradices on preferential root allocation may be related to its apparent capacity to downregulate or even inhibit $\mathrm{P}$ transporters in root cell membranes (Smith et al. 2004). As a result, the sensitivity of roots 
Table 3 Precision of intraradical and extraradical hyphae allocation, analyzed in terms of intraradical and extraradical LSU copy numbers per unit root mass, as well as extraradical LSU copy numbers per unit soil mass for the four P treatments: no fertilization (0 P HOM), homogeneous P supply (28 P HOM), low heterogeneous $\mathrm{P}$ supply (9.3 P HET), high heterogeneous $\mathrm{P}$ supply (28 P HET)

\begin{tabular}{|c|c|c|c|c|c|c|c|c|c|c|c|}
\hline & & \multirow{2}{*}{\multicolumn{3}{|c|}{$\begin{array}{l}\text { Precision of intraradical AMF } \\
\text { allocation } \\
\begin{array}{l}\text { LSU copy number } \\
\mathrm{mg}^{-1} \text { root dry weight }\end{array}\end{array}$}} & \multicolumn{6}{|c|}{ Precision of extraradical AMF allocation } & \\
\hline & & & & & \multicolumn{3}{|c|}{$\begin{array}{l}\text { LSU copy numbers } \\
\mathrm{mg}^{-1} \text { soil }\end{array}$} & \multicolumn{3}{|c|}{$\begin{array}{l}\text { LSU copy number } \\
\mathrm{mg}^{-1} \text { root dry weight }\end{array}$} & \\
\hline & & Prec. & Std.e. & P-value & Prec. & Std.e. & P-value & Prec. & Std.e. & $P$-value & \\
\hline \multirow[t]{4}{*}{ G. claroideum } & 0 P HOM & -0.13 & 0.67 & 0.852 & 0.15 & 0.12 & 0.255 & 2.11 & 0.67 & $0.009 * *$ & a \\
\hline & $28 \mathrm{P} \mathrm{HOM}$ & 0.93 & 0.67 & 0.200 & 0.05 & 0.12 & 0.706 & 0.28 & 0.67 & 0.685 & $\mathrm{ab}$ \\
\hline & 9.3 P HET & -0.19 & 0.78 & 0.816 & -0.08 & 0.14 & 0.609 & -1.08 & 0.77 & 0.191 & $\mathrm{~b}$ \\
\hline & 28 P HET & -0.63 & 0.78 & 0.436 & -0.25 & 0.12 & 0.073 & -1.80 & 0.67 & $0.021 *$ & $\mathrm{~b}$ \\
\hline \multirow[t]{4}{*}{ G. mosseae } & 0 P HOM & 0.57 & 0.52 & 0.301 & -0.01 & 0.26 & 0.960 & 0.18 & 0.28 & 0.536 & \\
\hline & $28 \mathrm{P} \mathrm{HOM}$ & 0.16 & 0.52 & 0.761 & 0.29 & 0.26 & 0.286 & 0.34 & 0.28 & 0.250 & \\
\hline & 9.3 P HET & -0.30 & 0.61 & 0.627 & -0.03 & 0.30 & 0.929 & -0.24 & 0.33 & 0.475 & \\
\hline & 28 P HET & -0.37 & 0.61 & 0.557 & -0.02 & 0.26 & 0.955 & -0.07 & 0.28 & 0.817 & \\
\hline \multirow[t]{4}{*}{ G. intraradices (nuclear DNA) } & 0 P HOM & -0.69 & 0.58 & 0.257 & -0.32 & 0.11 & $0.013 *$ & -1.71 & 0.72 & $0.035^{*}$ & \\
\hline & 28 P HOM & 0.06 & 0.58 & 0.924 & -0.32 & 0.11 & $0.013 *$ & -1.80 & 0.72 & $0.028 *$ & \\
\hline & 9.3 P HET & -0.22 & 0.67 & 0.714 & -0.17 & 0.11 & 0.152 & -0.67 & 0.72 & 0.375 & \\
\hline & $28 \mathrm{P}$ HET & -0.10 & 0.58 & 0.130 & -0.26 & 0.11 & $0.036^{*}$ & -1.07 & 0.72 & 0.165 & \\
\hline \multirow[t]{4}{*}{ (mitochondrial DNA) } & 0 P HOM & -0.66 & 0.43 & 0.156 & -0.05 & 0.16 & 0.815 & -0.35 & 0.94 & 0.721 & \\
\hline & $28 \mathrm{P} \mathrm{HOM}$ & -0.19 & 0.43 & 0.666 & 0.04 & 0.16 & 0.786 & -0.15 & 0.94 & 0.879 & \\
\hline & 9.3 P HET & -0.53 & 0.50 & 0.312 & 0.18 & 0.16 & 0.274 & 1.13 & 0.94 & 0.254 & \\
\hline & 28 P HET & -0.08 & 0.43 & 0.848 & -0.39 & 0.16 & $0.030 *$ & -1.55 & 0.94 & 0.125 & \\
\hline
\end{tabular}

LSU copy numbers for G. claroideum and G. mossea were determined in the treatments inoculated with the indigenous AMF mixture. Mitochondrial and nuclear LSU copy numbers of $G$. intraradices were determined only for the treatments in which the soil was inoculated with $G$. intraradices alone. The precision values give the differences in respective copy numbers between right and left lateral soil sections divided by the respective total LSU copy number in the entire container. Positive values indicate preferential hyphae allocation in the P-enriched soil sections in the heterogeneous P treatments. Regression analysis was used to assess if precision was significantly different from zero: $* p<0.05, * * p<0.01$. Different letters indicate significant differences between means according to least significant difference (LSD) multiple range post-hoc test following ANOVA $(p<0.05)$

for the detection of soil $\mathrm{P}$ gradients and thus the plant's capacity to respond to them with preferential growth could be strongly reduced. Smith et al. (2004) showed that in association with $G$. intraradices, Linum usitatissimum L., Medicago trucatula L. and Lycopersicon esculentum Mil. acquired 80-100 \% of their $\mathrm{P}$ via the fungus, while fungal contribution to $\mathrm{P}$ acquisition was much less in association with $G$. caledonium and Gigaspora rosea. The sensitivity of plants to detect $\mathrm{P}$ gradients in soil might also be reduced due to $\mathrm{P}$ depletion in the rhizosphere as a result of hyphal P uptake. Li et al. (1991) found that P concentrations around mycorrhizal Trifolium repens L. roots were much lower than around non-mycorrhizal roots for white clover.
Plants associated with indigenous AMF mixture can cope better with heterogeneous $\mathrm{P}$ distribution in soil than in association with G. intraradices alone

In soil with homogeneous $\mathrm{P}$ distribution, the treatments with $G$. intraradices or the mycorrhizal mixture did not significantly differ in their effects on plant biomass and $\mathrm{P}$ accumulation, suggesting that both mycorrhizal treatments had similar effects on plant $P$ acquisition under these conditions. In contrast to the homogeneous treatments, heterogeneous $\mathrm{P}$ fertilization increased biomass production only in the treatments with indigenous AMF mixture, but not in the $G$. intraradices treatments. The difference suggests that 

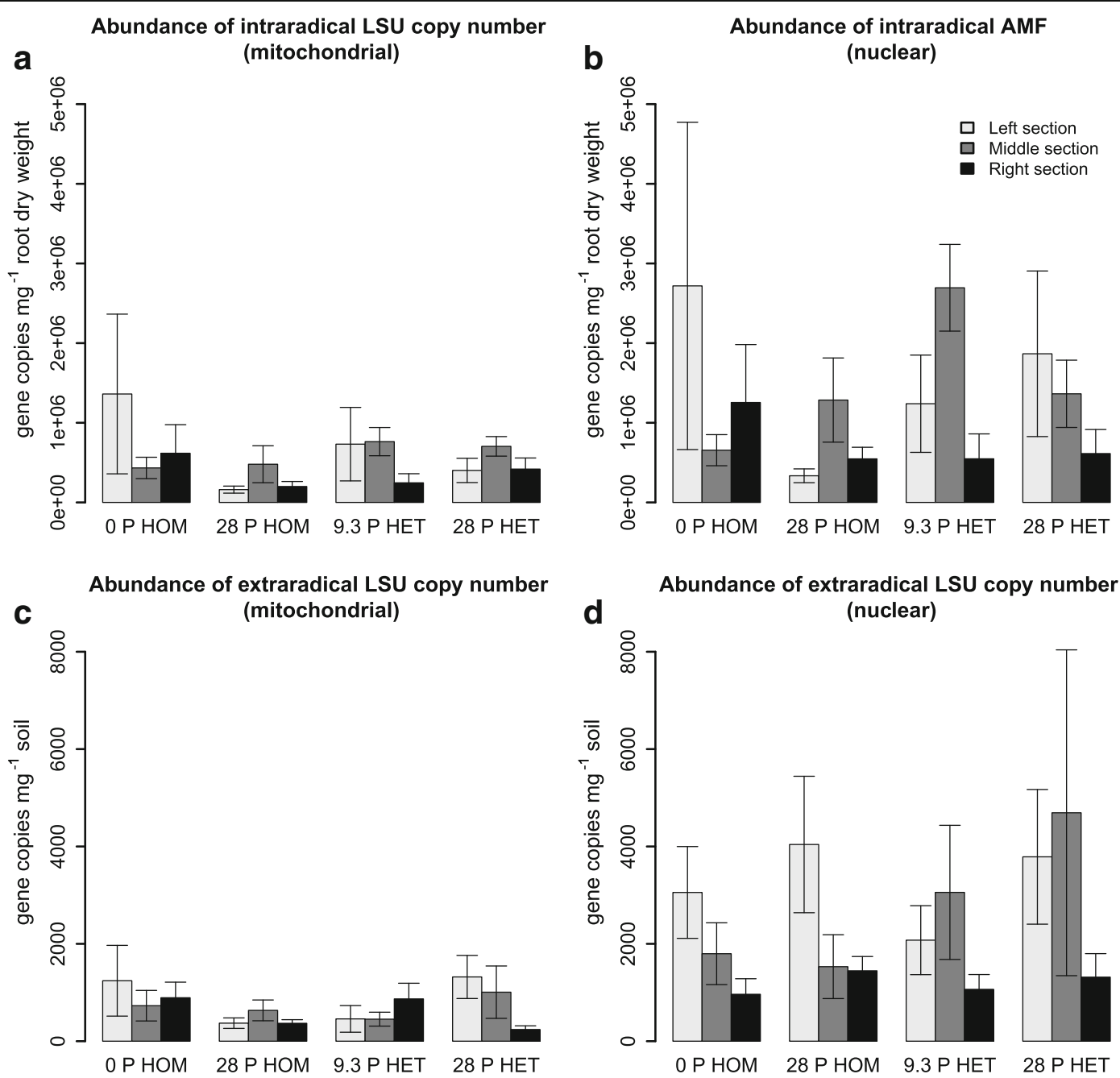

Fig. 4 Abundances of $G$. intraradices hyphae, given in terms of intraradical mitochondrial (a) and extraradical mitochondrial (c), as well as intraradical nuclear (b) and extraradical nuclear (d) LSU copy numbers, in soil inoculated with $G$. intraradices after sterilization in the three sections of the containers (LS left,

there were AMF species in the mycorrhizal mixture that were more beneficial for the experimental plants than $G$. intraradices in soil with heterogeneous $\mathrm{P}$ distribution. This would be consistent with the hypothesis that $G$. intraradices had an inhibiting effect on the direct uptake of soil $\mathrm{P}$ by the roots and that $\mathrm{P}$ absorbed by the fungus was partially retained in the fungal tissue. The plants growing in the homogeneously fertilized treatment had the advantage that they had access to P-enriched soil right from the beginning of the experiment and thus could have developed a stronger root system than in the other P treatments before being colonized by the fungus.

MS middle, RS right) for the four $\mathrm{P}$ treatments: no fertilization (0 P HOM), homogeneous P supply (28 P HOM), low heterogeneous P supply (9.3 P HET), high heterogeneous P supply (28 $\mathrm{P}$ HET). In the heterogeneous $\mathrm{P}$ treatments $\mathrm{P}$ was added only to the right sections (RS)

The difference between $G$. intraradices and indigenous AMF treatments may have also been due to AMF species in the mixture of indigenous AMF that were able to develop faster and explore the P-enriched soil at an earlier stage in the experiment than $G$. intraradices. Jakobsen et al. (1992) demonstrated that Acaulospora laevis hyphae spread faster and further away from Trifolium subterraneum roots than hyphae of Glomus species and acquired more $\mathrm{P}$ at greater distances from the root surface. Preferential allocation of hyphae may have been another factor contributing to the difference in AMF effects on plant growth in the heterogeneous $\mathrm{P}$ treatments. Although no preferential hyphal growth was 

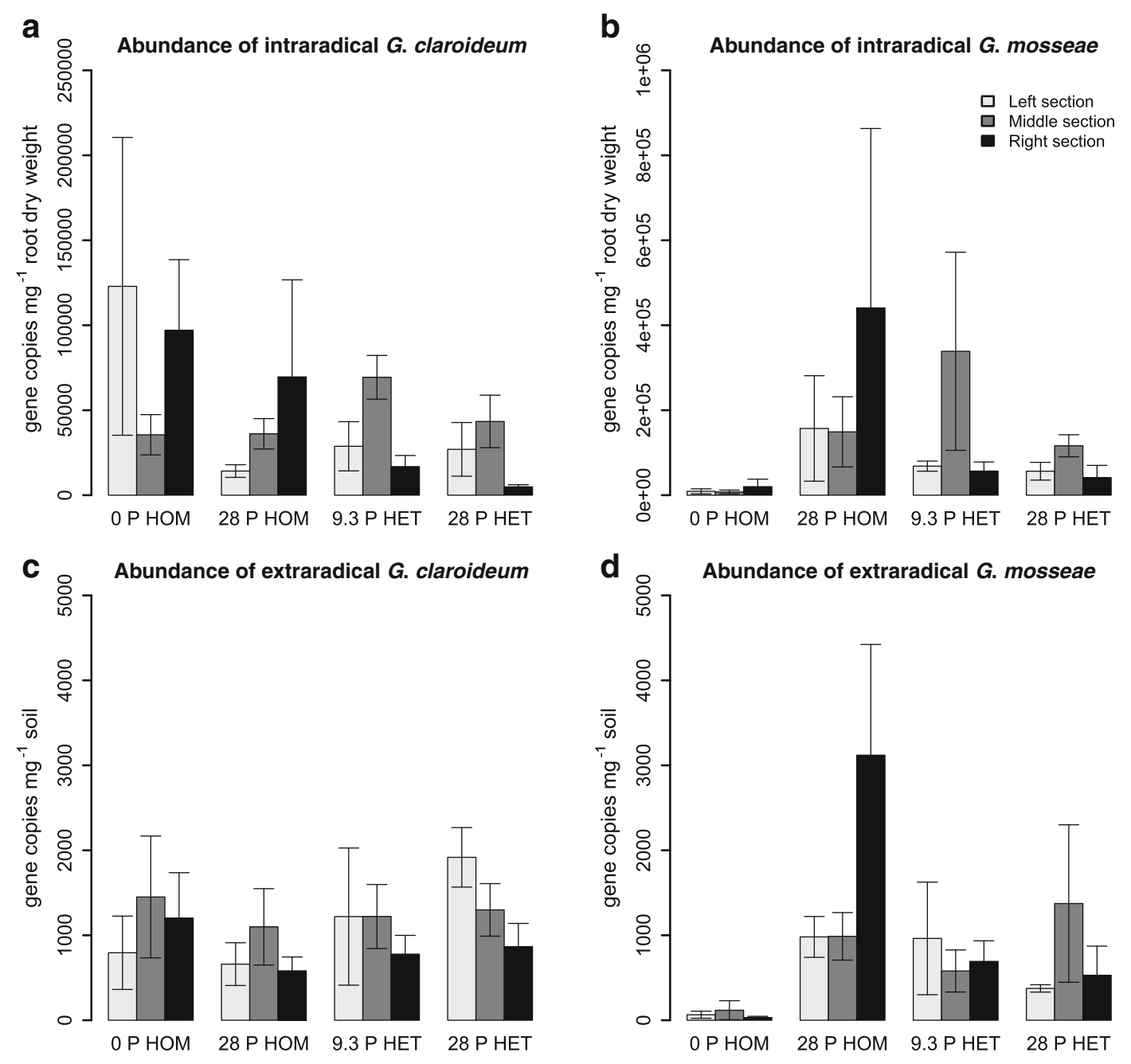

Fig. 5 Abundances of G. claroideum (a, c) and G. mosseae (b, d) hyphae, given in terms of Intraradical $(\mathbf{a}, \mathbf{b})$ and extraradical $(\mathbf{c}, \mathbf{d})$ LSU copy numbers, in soil re-inoculated with indigenous AMF after sterilization in the three sections of the containers (LS left, MS middle, RS right) for the four $\mathrm{P}$ treatments: no fertilization ( $0 \mathrm{P}$

detected in the analyzed AMF species, there may have been other species in the inoculum of indigenous AMF that responded by preferential hyphal allocation in the P-enriched soil sections.

The effect of $P$ fertilization on mycorrhizal abundance differed between AMF species

If mitochondrial LSU copy numbers are taken as a proxy for fungal biomass, then homogeneous P fertilization did not stimulate extraradical hyphal growth of G. intraradices, although it promoted root and shoot

biomass production. This is consistent with the findings of previous studies and also with optimal resource utilization theory, which predicts that plants should devote less assimilates to the fungus and more to the roots when metabolic costs decrease for direct $\mathrm{P}$ acquisition by the roots (Smith et al. 2011). It is not possible to determine if there was a similar trend with $\mathrm{P}$ application in the relationship between root and fungal biomass in the indigenous AMF treatments, because only two AMF species out of an unknown number of AMF species colonizing L. japonicus were analyzed; but the results show that $\mathrm{P}$ effects on hyphal 
growth can differ between AMF species. While there was no significant influence of $\mathrm{P}$ fertilization on the abundance of $G$. claroideum, the abundance of $G$. mosseae was strongly increased by $\mathrm{P}$ fertilization. Our results are in line with previous findings that $\mathrm{P}$ fertilization effects on fungal growth can vary considerably between AMF species (Graham and Abbott 2000; Cavagnaro et al. 2005) and that in soils extremely poor in available $\mathrm{P}$ low rates of $\mathrm{P}$ fertilization can even increase extraradical and intraradical hyphal production in a mycorrhizal fungus (Abbott et al. 1984). When roots are colonized by a mixture of AMF species plants can selectively reward those fungi with assimilates that deliver most $\mathrm{P}$ per unit of carbon, while withholding assimilates from AMF species providing $\mathrm{P}$ at higher $\mathrm{C}$ costs (Kiers et al. 2011). As plant assimilate allocation to $\mathrm{P}$ acquisition from AMF depends on plant $\mathrm{P}$ status and direct soil $\mathrm{P}$ uptake by roots, it can be expected that the relative competitive strength of AMF species will change with soil $\mathrm{P}$ availability and accessibility.

The lack of clear treatment effects on the spatial distribution of LSU copies between fertilized and unfertilized soil indicates that the analyzed AMF species did not respond to soil $\mathrm{P}$ heterogeneity with preferential hyphal growth. This was not to be expected under conditions where plant growth was still P-limited. Few experiments have investigated preferential hyphal growth in soil. (Cavagnaro et al. 2005; Cui and Caldwell 1996; Gavito and Olsen 2003; Shi et al. 2011). Their results indicate that hyphal growth patterns vary considerably with experimental conditions, host plant and AMF species. Contrary to our results, Gavito and Olsen (2003) found increased hyphal length density in soil patches enriched in $\mathrm{P}$ in $G$. intraradices and Scutellospora calospora associated with Trifolium subterraneum. Also Shi et al. (2011) showed that $G$. intraradices, $G$. etunicatum and G. mosseae preferentially grew hyphae into P-enriched soil patches, while Cavagnaro et al. (2005) found preferential hyphal growth in $G$. intraradices, but not in G. mosseae or Gigaspora rosea. In contrast to our study, however, plant roots were kept out of the P-enriched soil patches by means of screens that only allowed the fungal hyphae to pass. Thus, there was no direct competition between roots and hyphae for $\mathrm{P}$ in these patches, which might have favoured preferential hyphal growth into them to exploit this 'monopole position'.

The main finding of this study is that interactions with mycorrhizal fungi may completely override preferential root growth responses of plants to P patchiness in soil. It appears that this effect was primarily due to the fact that the plants could acquire sufficient $\mathrm{P}$ via the AMF to satisfy their demand for growth. The advantage of such a 'delegation' of nutrient acquisition is that it gives roots more freedom to explore a larger soil volume and forage for other resources in demand for growth. Our results furthermore show that hosting a larger variety of mycorrhizal fungi was most beneficial for the plants under conditions of heterogeneous P distribution, while there was no added advantage compared to the colonization with one species alone in the homogeneous $\mathrm{P}$ treatments, indicating that the main benefit for plants of association with multiple-species AMF in comparison to mono-colonization is an enhanced capacity of the plants to adapt to variable soil conditions.

Acknowledgments The study was part of the Transregional Collaborative Research Centre 38 (Gerwin et al. 2009). Angela Erb conducted the qPCR analyses. We gratefully acknowledge financial support by the German Research Foundation (DFG) and the Ministry of Science, Research and Culture of Brandenburg (MWFK, Potsdam).

\section{References}

Abbott LK, Robson AD, Deboer G (1984) The effect of phosphorus on the formation of hyphae in soil by the vesicular arbuscular mycorrhizal fungus, Glomus-fasciculatum. New Phytol 97(3):437-446

Cavagnaro TR, Smith FA, Smith SE, Jakobsen I (2005) Functional diversity in arbuscular mycorrhizas: exploitation of soil patches with different phosphate enrichment differs among fungal species. Plant Cell Environ 28(5):642-650

Couillerot O, Ramírez-Trujillo A, Walker V, von Felten A, Jansa J, Maurhofer M, Défago G, Prigent-Combaret C, Comte G, Caballero-Mellado J, Moënne-Loccoz Y (2012) Comparison of prominent Azospirillum strains in Azospirillum-pseudomonas-Glomus consortia for promotion of maize growth. Appl Microbiol Biotechnol. doi:10.1007/s00253-012-4249-z

Cui M, Caldwell MM (1996) Facilitation of plant phosphate acquisition by arbuscular mycorrhizas from enriched soil patches.1. Roots and hyphae exploiting the same soil volume. New Phytol 133(3):453-460

Demiranda JCC, Harris PJ, Wild A (1989) Effects of soil and plant phosphorus concentrations on vesicular-arbuscular mycorrhiza in sorghum plants. New Phytol 112(3):405-410

Einsmann JC, Jones RH, Pu M, Mitchell RJ (1999) Nutrient foraging traits in 10 co-occurring plant species of contrasting life forms. J Ecol 87(4):609-619

FAL, RAC, FAW. (1996a) Determination of carbonate $\left(\mathrm{CaCO}_{3}\right)$ Swiss reference methods of the Federal Agricultural Research Stations, Swiss Federal Research Station FAL, RAC, FAW, Zurich, Switzerland 
FAL, RAC, FAW. (1996b) Determination of grain size in the mineral content of fine soil. Swiss reference methods of the Federal Agricultural Research Stations, Swiss Federal Research Station FAL, RAC, FAW, Zurich, Switzerland

FAL, RAC, FAW. (1996c) Determination of organic carbon $\left(\mathrm{C}_{\mathrm{org}}\right)$. Swiss reference methods of the Federal Agricultural Research stations, Swiss Federal Research Station FAL, RAC, FAW, Zurich, Switzerland

FAL, RAC, FAW. (1996d) Ph in water suspension (1:2.5) and ph in $\mathrm{CaCl}_{2}$ suspension $(1: 2.5)$. Swiss reference methods of the Federal Agricultural Research stations, Swiss Federal Research Station FAL, RAC, FAW, Zurich, Switzerland

Farley RA, Fitter AH (1999) The responses of seven cooccurring woodland herbaceous perennials to localized nutrient-rich patches. J Ecol 87(5):849-859

Gavito ME, Olsson PA (2003) Allocation of plant carbon to foraging and storage in arbuscular mycorrhizal fungi. FEMS Microbiol Ecol 45:181-187

Gerwin W, Schaaf W, Biemelt D, Fischer A, Winter S, Huettl RF (2009) The artificial catchment chicken creek (Lusatia, Germany) - a landscape laboratory for interdisciplinary studies of initial ecosystem development. Ecol Eng 35:1786-1796

Gleeson SK, Tilman D (1992) Plant allocation and the multiple limitation hypothesis. Am Nat 139:1322-1343

Graham JH, Abbott LK (2000) Wheat responses to aggressive and non-aggressive arbuscular mycorrhizal fungi. Plant Soil 220(1-2):207-218

Gryndler M, Trilčová J, Hršelová H, Streiblová E, Gryndlerová H, Jansa J (2012) Tuber aestivum vittad. mycelium quantified: Advantages and limitations of a qPCR approach. Mycorrhiza:1-8. doi:10.1007/s00572-012-0475-6

Hinsinger P (2001) Bioavailability of soil inorganic p in the rhizosphere as affected by root-induced chemical changes: A review. Plant Soil 237:173-195

Hodge A Plastic plants and patchy soils. In: Meeting on phenotypic plasticity and the changing environment held at the Society for Experimental Biology Plant Frontiers Meeting, Sheffield, England, Mar 20-23 2005. Oxford Univ Press, pp 401-411. doi:10.1093/jxb/eri280

Jackson RB, Caldwell MM (1993) The scale of nutrient heterogeneity around individual plants and its quantification with geostatistics. Ecology 74(2):612-614

Jackson RB, Manwaring JH, Caldwell MM (1990) Rapid physiological adjustment of roots to localized soil enrichment. Nature 344(6261):58-60

Jakobsen I, Abbott LK, Robson AD (1992) External hyphae of vesicular-arbuscular mycorrhizal fungi associated with trifolium-subterraneum L..1. Spread of hyphae and phosphorus inflow into roots. New Phytol 120(3):371-380

Jansa J, Smith FA, Smith SE (2008) Are there benefits of simultaneous root colonization by different arbuscular mycorrhizal fungi? New Phytol 177(3):779-789. doi:10.1111/ j.1469-8137.2007.02294.x

Johnson NC, Graham JH, Smith FA (1997) Functioning of mycorrhizal associations along the mutualism-parasitism continuum. New Phytol 135(4):575-586. doi:10.1046/ j.1469-8137.1997.00729.x

Kiers ET, Duhamel M, Beesetty Y, Mensah JA, Franken O, Verbruggen E, Fellbaum CR, Kowalchuk GA, Hart MM, Bago A, Palmer TM, West SA, Vandenkoornhuyse P, Jansa J, Buecking H (2011) Reciprocal rewards stabilize cooperation in the mycorrhizal symbiosis. Science 333(6044):880-882. doi:10.1126/science.1208473

Kovar JL, Barber SA (1989) Reasons for differences among soils in placement of phosphorus for maximum predicted uptake. Soil Sci Soc Am J 53(6):1733-1736

Kume T, Sekiya N, Yano K (2006) Heterogeneity in spatial Pdistribution and foraging capability by Zea mays: effects of patch size and barriers to restrict root proliferation within a patch. Ann Bot 98(6):1271-1277. doi:10.1093/aob/mcl216-5

Li XL, George E, Marschner H (1991) Phosphorus depletion and ph decrease at the root soil and hyphae soil interfaces of VA mycorrhizal white clover fertilized with ammonium. New Phytol 119(3):397-404. doi:10.1111/j.1469-8137.1991. tb00039.x

Ma Q, Rengel Z (2008) Phosphorus acquisition and wheat growth are influenced by shoot phosphorus status and soil phosphorus distribution in a split-root system. J Plant Nutr Soil Sci-Zeitschrift Fur Pflanzenernahrung Und Bodenkunde 171(2):266-271. doi:10.1002/jpln.200700183

Olsen SR, Cole CV, Watanabe FS, Dean LA (1954) Estimation of available phosphorus in soils by extraction with sodium bicarbonate. U S Dept Agric Circ 939:1-19

Robinson D (1994) The responses of plants to nonuniform supplies of nutrients. New Phytol 127(4):635-674

Schweiger PF, Robson AD, Barrow NJ (1995) Root hair length determines beneficial effect of a Glomus species on shoot growth of some pasture species. New Phytol 131(2):247-254

Shi ZY, Wang FY, Zhang C, Yang ZB (2011) Exploitation of phosphorus patches with different phosphorus enrichment by three arbuscular mycorrhizal fungi. J Plant Nutr 34(8):1096-1106. doi:10.1080/01904167.2011.558154

Smith SE, Read D (2008) Mycorrhizal symbiosis. Academic, London

Smith SE, Smith FA, Jakobsen I (2004) Functional diversity in arbuscular mycorrhizal (AM) symbioses: the contribution of the mycorrhizal P uptake pathway is not correlated with mycorrhizal responses in growth or total P uptake. New Phytol 162(2):511-524. doi:10.1111/j.1469-8137.2004.01039.x

Smith FA, Grace EJ, Smith SE (2009) More than a carbon economy: nutrient trade and ecological sustainability in facultative arbuscular mycorrhizal symbioses. New Phytol 182(2):347-358. doi:10.1111/j.1469-8137.2008.02753.x

Smith SE, Jakobsen I, Gronlund M, Smith FA (2011) Roles of arbuscular mycorrhizas in plant phosphorus nutrition: interactions between pathways of phosphorus uptake in arbuscular mycorrhizal roots have important implications for understanding and manipulating plant phosphorus acquisition. Plant Physiol 156(3):1050-1057. doi:10.1104/pp. 111.174581

Team RDC (2008) R: A language and environment for statistical computing

Thonar C, Erb A, Jansa J (2012) Real-time PCR to quantify composition of arbuscular mycorrhizal fungal communities - marker design, verification, calibration and field validation. Mol Ecol Resour 12(2):219-232. doi:10.1111/j.1755-0998.2011.03086.x

Tibbett M (2000) Roots, foraging and the exploitation of soil nutrient patches: the role of mycorrhizal symbiosis. Funct Ecol 14:397-399

Wijesinghe DK, Hutchings MJ (1999) The effects of environmental heterogeneity on the performance of Glechoma hederacea: the interactions between patch contrast and patch scale. J Ecol 87(5):860-872 